\title{
Effective pulmonary blood flow in normal children at
} rest

\author{
J J BOWYER, J O WARNER, D M DENISON
}

From the Departments of Clinical Physiology and Paediatrics, Brompton Hospital, London

ABSTRACT Effective pulmonary blood flow was measured with a soluble inert gas uptake method ( $10 \%$ argon, $3.5 \%$ freon- $22,35 \%$ oxygen, balance nitrogen) in 98 apparently healthy childred aged $5-$ 14 years. None had any evidence of cardiorespiratory disease and all had normal values for absolute and dynamic lung volumes and transfer factor for carbon monoxide. Values of blood flow measured by a rebreathing method correlated reasonably closely with height, weight, body surface area, and lung volumes, and to a lesser extent with hand and foot size. The mean (SD) effective pulmonary blood flow index was $2.7(0.31) 1 \mathrm{~min}^{-1} \mathrm{~m}^{-2}$. Small children found a single breath method of measuring flow more difficult to perform and the results were more variable.

\section{Introduction}

Respiratory methods for the determination of pulmonary blood flow estimate that part of the flow through lung capillaries which is effective in gas exchange. The principle of using soluble gas uptake to calculate this fraction was invented by Humphrey Davy in 1840 and developed by several people, notably Grollman, ${ }^{1}$ Cander and Forster, ${ }^{2}$ Teichman et al, ${ }^{3}$ and Sackner. ${ }^{4}$ Soluble inert gas is removed from alveolar air at an exponential rate that is proportional to blood flow and the solubility of the gas in blood. Initially this process is complicated by gas mixing. Later it is disturbed by the recirculation of contaminated blood. When the logarithmic concentration of test gas in alveolar air is plotted against time the artefact free period between mixing and recirculation is recognised as a log-linear fall, from which the flow of blood effecting gas removal can be calculated. It is called effective pulmonary blood flow. The particular effective pulmonary blood flow variants of the principle used here are the rebreathing method and the single breath uptake of an argon-freon-22 mixture described by Denison $e t$ al. ${ }^{56}$ Both techniques are non-invasive and are suitable for use in children.

Since heart catheterisation became feasible the Direct Fick method of estimating cardiac output has become the most acceptable invasive way of assessing children with heart disease,' but data in normal

Address for reprint requests: Dr J Bowyer, Department of Paediatrics, St Peter's Hospital, Chertsey, Surrey KT1\% 0PZ.

Accepted 31 August 1988 children are understandably limited. The findings of Brotmacher and Felming ${ }^{8}$ are commonly used. Several workers have obtained non-invasive estimates of pulmonary blood flow in children, using respired soluble inert gas or carbon dioxide techniques. Godfrey $e t$ al and Zeidifard ${ }^{10}$ measured pulmonary blood flow at rest and during exercise and found that the relation of blood flow to oxygen consumption was the same in children and adults. Chu et al $^{11}$ and Cotton ${ }^{12}$ have applied the method in neonates to study blood flow in the respiratory distress syndrome. None of these investigations, however, has provided sufficient data to establish normal values for children at rest. The present study describes rebreathing and single breath measurements of effective pulmonary blood flow $\left(\mathrm{QP}_{\mathrm{eff}}\right)$ in a total of 98 healthy schoolchildren from London.

\section{Methods}

\section{SUBJECTS}

The subjects, 53 girls and 45 boys aged 5-14 years, came from private schools in London, and are part of a larger study of respiratory function in healthy children (in preparation). Informed consent was obtained from the parents, who were also asked to complete a detailed questionnaire on past medical history, family history, and prevalence of smoking in the household. Each child was examined on the day of the tests for current disease of the respiratory tract and the presence of cardiac murmurs. Any child with a significant history of cardiorespiratory illness, particularly asthma, or with coryza or wheezing on the day, was excluded from the study. 


\section{ANTHROPOMETRY}

Each child was weighed and measured by the anthropometric techniques of Tanner and Whitehouse. ${ }^{13}$ Standing height was determined with a Harpenden stadiometer, and hand length (from the distal end of the radius to the tip of the middle finger) with a Harpenden anthropometer. Pubertal stage was noted. Body surface area was calculated from height and weight by means of the nomogram of Dubois. ${ }^{14}$

\section{LUNG FUNCTION TESTS}

Total lung capacity (TLC) and residual volume (RV) were determined by constant volume whole body plethysmography ${ }^{15}$ (Pulmostar SMB, Fenyves and Gut). A dead space adapter $(40 \mathrm{ml})$ was used for children who had a tidal volume of $300 \mathrm{ml}$ or less. No correction was made for abdominal gas. The transfer factor for carbon monoxide (TLCO) was measured (transfer test machine PK Morgan, series B) by the 10 second single breath procedure of Ogilvie et al. ${ }^{16}$ In seven children with a vital capacity of $700 \mathrm{ml}$ or less the rebreathing procedure of Lewis ${ }^{17}$ was used. Combined inspiratory and expiratory maximal flowvolume loops were recorded, an Ohio 810 rolling seal spirometer being used.

\section{EFFECTIVE PULMONARY BLOOD FLOW}

Effective pulmonary blood flow was measured on the morning the other tests were done, when the subjects had sat and rested for at least 10 minutes, one hour or more after their normal breakfast. Most children did both the rebreathing and the single breath tests, in random order, with an interval of 10 minutes between the two tests. For both methods a mixture of $10 \%$ argon, $3.5 \%$ difluoromonochloromethane (freon-22) and $35 \%$ oxygen in nitrogen was breathed. The changing fractional concentrations of these gases with time were recorded continuously by respiratory mass spectrometry (Centronics MGA 200 analyser). The machine had a sample flow of $60 \mathrm{ml} / \mathrm{min}$ and a $95 \%$ response time of $0 \cdot 2$ second.

For the rebreathing estimate a rebreathing bag fitted with a half Haldane tap was filled with a measured volume of gas mixture, corresponding to about $80 \%$ of the subject's vital capacity. Subjects were asked to exhale to residual volume and then rebreathe deeply from the bag about 15 times over the ensuing 20-30 seconds. For the single breath procedure the bag was filled in the same way and subjects were asked to exhale to RV, inhale to TLC, hold their breath for two or three seconds, and then exhale at about $90 \mathrm{ml} / \mathrm{s}$ to reach RV some 20 seconds later. To help the children achieve a steady rate of expiration a volume trace and target ramp were presented to their field of view. The pen records of gas concentrations from both procedures were analysed as described previously. ${ }^{56}$

\section{PRELIMINARY STUDIES}

The final study design was influenced by the findings in several preliminary experiments. Some of these were done with adult subjects, who could more reasonably be asked to do repeated tests than children.The main findings in the preliminary studies were:

1 Studies in adults showed that if the measurement of pulmonary blood flow was repeated at 3.5 minute intervals estimates of blood flow were stable after the first two measurements.

2 So that we could examine the effects of varying inspired volume, four adults repeated the rebreathing and single breath procedures using an inspired volume corresponding to $75 \%$ and $100 \%$ of vital capacity. This made no significant difference to the calculated blood flow, the mean difference being only $0.11 \mathrm{~min}^{-1}$ for rebreathing and $0.21 \mathrm{~min}^{-1}$ for the single breath test.

3 The effect of varying the rate of expiration from 0.05 to 0.1 and $0.151 \mathrm{~s}^{-1}$ was investigated in six adults. A difference in the calculated flow was found in all subjects, with a mean value of $5.41 \mathrm{~min}^{-1}$ at the slower rate, $6.31 \mathrm{~min}^{-1}$ at the medium rate, and $6.71 \mathrm{~min}^{-1}$ at the fastest rate of exhalation. As children were not able to control their rate of expiration very precisely, we accepted that this might be a cause of variability in their single breath results.

4 To examine the effects of recirculation during rebreathing, we analysed 59 traces in 22 children from the start of the linear record to the 15th, 20th, and 25th second of the manoeuvre. There were no significant differences between the calculated results to the 15 th and 20th second but there was a fall of $4.5 \%$ by the 25 th second. The time limit to trace analysis was therefore set at 20 seconds.

5 The day to day variability in the estimates of pulmonary blood flow was studied in seven children who repeated the tests at the same time on three consecutive days. For the rebreathing test the coefficient of variation within each set of measurements was $6.7 \%$ and the day to day coefficient of variation of the mean value was $4.8 \%$. For the single breath test the coefficient of variation within each set was $8.8 \%$ and the coefficient of variation between days $6.0 \%$.

As a result of the pilot studies 98 children in the formal study were asked to perform at least five timed rebreathing and single breath tests. The third, fourth, and fifth traces were used to calculate effective pulmonary blood flow. Where one of these was clearly unsatisfactory, a sixth and occasionally a seventh test was carried out. The inspired volume chosen for the rebreathing test was between $75 \%$ and $100 \%$ of vital capacity. 
CALCULATION OF RESULTS

A Numonics digitising tablet and a Prime 300 computer were used to analyse the data, employing the following steps:

1 The argon and freon traces were delineated, scaled, and aligned. The accessible lung volume was calculated from the dilution of the inspired argon.

2 The concentration of freon was expressed as a fraction of the simultaneous argon concentration for each end tidal point, and this fraction was plotted on a semilogarithmic scale against time. The computer program provided a visual display at this step, so that the linear portion of the log plot of freon uptake could be selected and measured.

3 The accessible lung water (Vw) and effective pulmonary blood flow $\mathrm{Q} p$ were then calculated from the following equations:

$$
\begin{gathered}
\mathrm{Vw}=(\mathrm{VA} / \mathrm{Sw})^{*}((100 / \mathrm{I})-1)^{*}(760 /(\mathrm{PB}-47)) \\
\mathrm{Qp}=\text { "slope"* }\left(\left(\left(\mathrm{VA}^{*} 760\right) /(\mathrm{PB}-47)+\mathrm{Sw} \mathrm{Vw}^{*}\right) / \mathrm{Sb}\right),
\end{gathered}
$$

where $\mathrm{Sw}$ and $\mathrm{Sb}$ are the Ostwald solubility coefficients of freon in water and blood respectively, I is the intercept of the linear part of the log plot with the time zero ordinate, and VA is the accessible gas volume of the lung. For the single breath trace the program includes a correction for diminishing lung volume. ${ }^{6}$

\section{ANALYSIS}

The study provided the following measurements on each child: (a) age, height, weight, hand and foot length, surface area estimate, and gender; $(b)$ total lung capacity, residual volume, forced expiratory volume in one second $\left(\mathrm{FEV}_{1}\right)$, forced vital capacity (FVC), TLCO, alveolar volume ( $\mathrm{V}_{\mathrm{A}}$ ), and transfer coefficient (KCO); (c) effective blood flow index determined by single breath or rebreathing procedures or both. This is the effective blood flow of the whole lung, divided by the body surface area, and is analogous to cardiac index.

Dynamic and static lung volumes and transfer factor for carbon monoxide were compared with the published values of Polgar and Promodhat ${ }^{18}$ Results were surveyed initially by regression analysis and then inspected by multiple stepwise linear regression.

\section{Results}

The ages of the children varied from 5 to 14 years, with a mean of 7.2 years for the 45 boys and 9.3 years for the 53 girls. Most of the 98 subjects were white, but seven came from the Middle East, one from India, one from Pakistan, one from Japan, and two from Africa. All but five boys were prepubertal; 14 of the 53 girls were in pubertal stages 2-4 and three were fully mature (stage 5). In general, the children were easy subjects who appeared to enjoy doing the tests. A full size
Table 1 Absolute and dynamic lung volumes and transfer factor for carbon monoxide ( $T L C O$ ) in 98 apparently healthy children aged 5-14 years

\begin{tabular}{lc}
\hline Variable & $\begin{array}{l}\text { Mean }(S D) \\
\left(\% \text { pred }^{18}\right)\end{array}$ \\
\hline FEV & $94.6(11 \cdot 7)$ \\
Forced vital capacity & $91 \cdot 9(12 \cdot 0)$ \\
Total lung capacity & $101 \cdot 1(11 \cdot 5)$ \\
Residual volume & $147 \cdot 3(46 \cdot 2)$ \\
TLCo & $101 \cdot 2(12 \cdot 2)$ \\
\hline
\end{tabular}

mouthpiece and nose clip presented no problem, even to the smallest, providing that they were allowed to put them on themselves.

Three children were not able or willing to complete the lung volume measurements in the body plethysmograph and have been excluded from the whole study. Four of the smallest children were unable to do $\mathbb{Q}$ the breath holding or steady exhalation required for $\overrightarrow{0}$ the single breath tests but are included in the rebreathing analyses. Small children were sometimes unable to signal that they had reached residual volume during exhalation, and the observer then had to judge when this had occurred. In four children the traces for the single breath test were considered to be unsuitable for analysis, usually because expiration was too fast or the argon trace indicated poor and variable gas mixing. Estimates of effective pulmonary blood flow were therefore available for the rebreathing technique for 89 children and for the single breath tests for 81 .

Values for FEV, FVC, TLC, and TLCo were close to those predicted by Polgar and Promodhat ${ }^{18}$ (table 1). The RV values are higher than predicted, but this was also true of a much larger group of children studied by the same methods in our laboratory. The data reviewed by Polgar and Promodhat were based on gas dilution estimates rather than plethysmography, and would be expected to be slightly smaller.

Table 2 Relation between rebreathing estimates of effective pulmonary blood flow ( $\mathrm{min}^{-1}$ ) and anthropometric data, $F E V$, and total lung capacity in healthy children aged 5-14 years: slope and intercept of the regression line and the

\begin{tabular}{|c|c|c|c|c|c|}
\hline$n$ & Variable & Slope & Intercept & $r$ & $\begin{array}{l}\text { SE of } \\
\text { estimate }\end{array}$ \\
\hline $\begin{array}{l}89 \\
89 \\
89 \\
89 \\
89 \\
86 \\
86\end{array}$ & $\begin{array}{l}\text { Height }(\mathrm{cm}) \\
\text { Weight }(\mathrm{kg}) \\
\text { Body surface area }\left(\mathrm{m}^{2}\right) \\
\text { Total lung capacity }(\mathrm{l}) \\
\text { FEV }(\mathrm{l}) \\
\text { Hand length }(\mathrm{cm}) \\
\text { Foot length }(\mathrm{cm})\end{array}$ & $\begin{array}{l}0.040 \\
0.057 \\
2.651 \\
0.687 \\
0.995 \\
0.273 \\
0.204\end{array}$ & $\begin{array}{l}-2 \cdot 536 \\
+1 \cdot 178 \\
+0.091 \\
+1 \cdot 031 \\
+1 \cdot 181 \\
-1 \cdot 142 \\
-1 \cdot 349\end{array}$ & $\begin{array}{l}0.76 \\
0.79 \\
0.80 \\
0.71 \\
0.73 \\
0.66 \\
0.67\end{array}$ & $\begin{array}{l}0.369 \\
0.347 \\
0.336 \\
0.402 \\
0.386 \\
0.399 \\
0.394\end{array}$ \\
\hline
\end{tabular}
regression correlation coefficient 
$\dot{Q}_{\mathrm{PRB}}$

$\left(1 \min ^{-1}\right)$

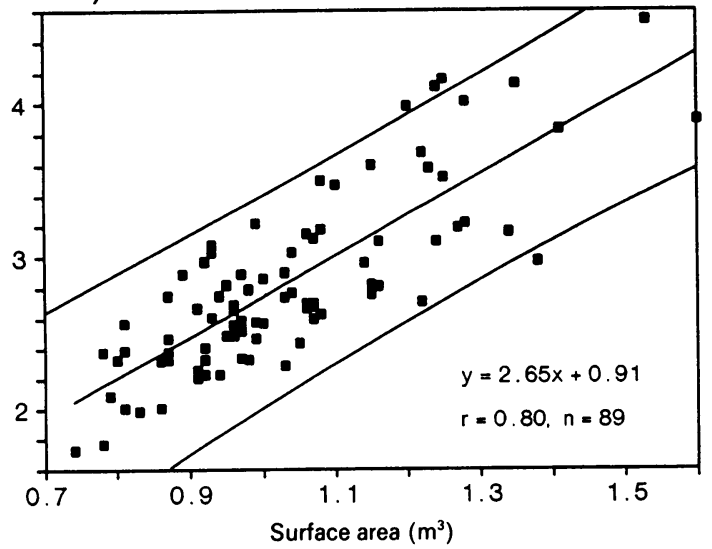

Fig 1 Relation between rebreathing estimates of effective pulmonary blood flow ( $\left(\mathrm{Q}_{\mathrm{RB}}\right.$ ) at rest and body surface area in 89 apparently healthy children. The regression line, $95 \%$ confidence limits, and regression equation for flow on body surface are shown.

\section{RELATION OF EFFECTIVE PULMONARY BLOOD} FLOW TO ANTHROPOMETRIC INDICES AND PULMONARY FUNCTION

The correlations between blood flow measured by the rebreathing method and anthropometric variables, $\mathrm{FEV}_{1}$, and TLC are given in table 2 . The rebreathing estimates of effective pulmonary blood flow showed a reasonably close relation to height, weight, $\mathrm{FEV}_{1}$, TLC, and surface area, but less so to hand and foot size. The relation of the rebreathing estimate of blood

$Q_{\text {PRB }}$

$\left(1 \mathrm{~min}^{-1}\right)$

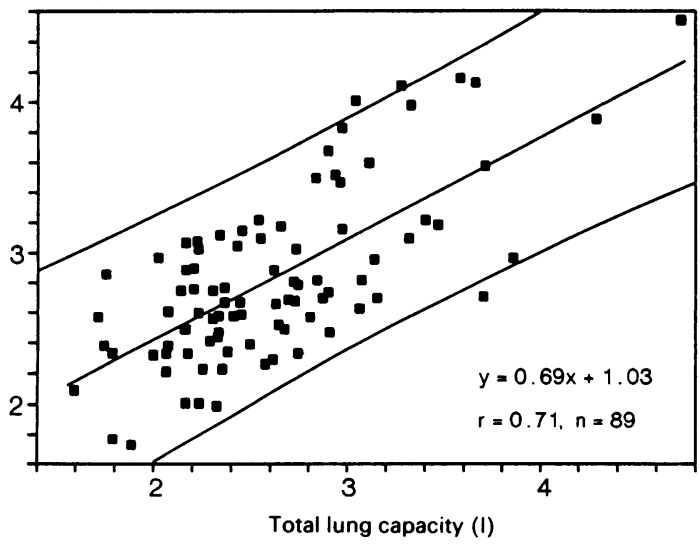

Fig 2 Relation between rebreathing estimate of effective pulmonary blood flow ( $\mathrm{Q}_{\mathrm{P}_{\mathrm{RB}}}$ ) at rest and total lung capacity in 89 apparently healthy children. The regression line, 95\% confidence limits, and regression equation for flow on total lung capacity are shown. flow to body surface area $(r=0.8)$ and to TLC $(r=$ 0.71 ) is shown in figures 1 and 2. The mean (SD) effective pulmonary blood flow index obtained from the rebreathing method was $2 \cdot 74(0 \cdot 31) 1 \mathrm{~min}^{-1} \mathrm{~m}^{-2}$, and was independent of height and age.

The relations of the anthropometric variables and

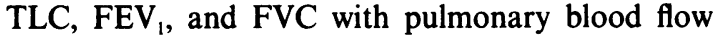
determined by the rebreathing method were also analysed by multiple stepwise regression. The closest correlation was provided by surface area, and no further variable improved the correlation. As surface area is calculated from two measurements, height and weight, it may be subject to greater error; so the analysis was repeated excluding it. Weight then provided the closest correlation $(r=0.75)$ and the final model was improved by the addition of $F^{2} V_{1}(r$ $=0.77$ ).

The relation between the single breath estimates of blood flow and body surface area was poor $(r=0.4)$ and similar to that for height and weight $(r=0.42$ and 0.36 respectively). The mean (SD) effective pulmonary blood flow index derived from single breath estimates was higher and more variable (3.94 (0.74) $\left.1 \mathrm{~min}^{-1} \mathrm{~m}^{-2}\right)$ but fell substantially with age, suggesting that the high values in young subjects were unreliable. The coefficients of variation for effective pulmonary blood flow index for sets of three acceptable measurements on each child were $6.3 \%$ for rebreathing manoeuvres and $8.0 \%$ for single breath procedures.

The expiratory rate calculated from the volume trace in the single breath tests varied between 0.07 and $0.31 \mathrm{~s}^{-1}$. Multiple regression analysis of effective pulmonary blood flow against height and expiratory rate gave the regression equation

$\mathrm{QP}_{\mathrm{eff}}=-0.32+0 \cdot 03^{*} \mathrm{Ht}(\mathrm{cm})+3 \cdot 0^{*} \exp$ flow $\left(1 \mathrm{~s}^{-1}\right)$.

Variation in expiratory rate accounted for half of the variability in results.

\section{Discussion}

The purpose of this study was to determine normal values for effective pulmonary blood flow in children at rest, and relate them to body size. For the rebreathing method normal values may be predicted with reasonable confidence from height, weight, or calculated surface area. The mean value of $2.741 \mathrm{~min}^{-1}$ $\mathrm{m}^{-2}$ is similar to other estimates using soluble gas methods, which range from $2 \cdot 2^{1}$ to $3 \cdot 31$. $^{2}$ Our mean, however, is consistently lower than Direct Fick estimates of the cardiac index-for example, 3.5, 3.6, and $4.31 \mathrm{~min}^{-1} \mathrm{~m}^{-2}$ cited by Barratt Boyes, ${ }^{19}$ Brandfonbrenner et $a l^{20}$ and Brotmacher and Felming $^{8}$ respectively. In part this is due to body position, as moving from the supine to the sitting posture reduces cardiac output by $5-20 \% .{ }^{21}$ Some $5 \%$ of blood flow apparently passes to unventilated alveoli and is 
excluded from respiratory estimates of pulmonary perfusion. ${ }^{22}$ Thus the differences in rebreathing and Direct Fick estimates can be accounted for.

For practical reasons this study was performed in children from private schools. We accept that their stature may differ slightly from the norms in Britain, but the relations between the measured anthropometric variables, lung volumes, and effective pulmonary blood flow are likely to be representative of all children.

The soluble inert gas methods assume that the mixed venous content of indicator gas is zero, and pulmonary end capillary blood and alveolar gas are in equilibrium. Dissolved gas in recirculating blood will disturb the log-linear relation of gas uptake in the lung with time. With our methods this was detected only after 20 seconds as the absorbed gas is taken up by peripheral tissues before it reappears in the lung. ${ }^{23}$ During successive manoeuvres at 3.5 minute intervals the end tidal concentration of freon- 22 measured at the start of each manoeuvre rose slightly but did not exceed $1.3 \%$ of the inspired concentration. A quasisteady state was usually established by the end of the third manoeuvre.

In some patients with cardiorespiratory disease early recirculation may occur through abnormal channels. One attraction of the single breath test is that it begins to provide useful information within four seconds of the onset of the manoeuvre. Unfortunately the results are substantially affected by the rate of expiration and it is difficult to fix this for some of the younger children.

Rebreathing creates a more homogeneous gas composition in the lung and minimises the effects of ventilation-perfusion inequality. In children with severe respiratory disease, with substantial areas of underventilation or ventilation-perfusion mismatch, the effective pulmonary blood flow is much lower than the total blood flow. ${ }^{24}$ Nevertheless, serial measurements may be valuable in showing a change in the potential for gas exchange. Hypoxia is avoided by using an oxygen rich initial gas mixture. Fairly deep breaths are used to achieve good gas mixing, although this is bound to cause some increase in pulmonary blood flow.

The effective pulmonary blood flow measured by these soluble gas methods is a reflection of the blood flow that is useful for respiratory gas exchange. The values obtained by the rebreathing method are reproducible in children and the ranges predicted from this study are closely related to body size. We hope that this information will be of use in assessing patients with cardiopulmonary disorders when heart catheterisation is inappropriate. The method is particularly suited to serial measurements of pulmonary blood flow-for example, in assessing the value of vaso- dilator treatment or the progression of kyphoscoliosis. Although the correlations with hand and foot sizes are not as close as those for weight and height, they may be useful in children with severe disorders of growth, such as osteogenesis imperfecta, and in children with spina bifida whose height cannot be measured.

We are most grateful to Mrs Sue Bain, Miss Caroline Busst, Mrs Vanessa White, and Mr Derek Cramer for invaluable help with anthropometry, respiratory mass spectrometry, routine lung function testing, and organisation of the trial respectively.

\section{References}

1 Grollman A. The determination of cardiac output of man by the use of acetylene. Am J Physiol 1929;88:432-45.

2 Cander L, Forster RE. Determination of pulmonary parenchyma tissue volume and pulmonary capillary blood flow in man. J Appl Physiol 1959;14:541-51.

3 Teichman H, Adaro F, Veicsteinas A, Cerretelli P, Piiper J. Determination of pulmonary blood flow by rebreathing of soluble inert gases. Respiration 1974;31:296-309.

4 Sackner MA, Greenletch D, Heiman MS, Epstein S, Atkins N. Diffusing capacity, membrane diffusing capacity, capillary blood volume, pulmonary tissue volume and cardiac output measured by rebreathing technique. Am Rev Respir Dis 1975;111:157-65.

5 Denison DM, Davies NJH, Brown D. A theoretical comparison of single-breath and rebreathing methods $\overrightarrow{\bar{O}}$ of studying soluble gas exchange in the lung. In: 3 Cumming G, Bonsignore G, eds. Pulmonary circulation $\supset$ in health and disease. New York: Plenum, 1980:139-48.

6 Denison DM, Davies NJH, Meyer M, Pierce RJ, Scheid $P$. Single exhalation method for the study of lobar and segmental lung function by mass spectrometry in man. Respir Physiol 1980;42:87-99.

7 Cournand A. Measurement of cardiac output in man using right heart catheterisation: description of technique, discussion of validity and place in the study of $\mathrm{O}$ the circulation. Fed Proc 1945;4:207-14.

8 Brotmacher L, Felming F. Cardiac output and vascular 윽 pressures in ten normal children and adolescents. Guy's Hospital Reports 1957;106:268.

9 Godfrey S, Davies CTM, Wosniak E, Barnes CA. Cardiorespiratory reponse to exercise in normal chil- o dren. Clin Sci 1971;40:419-31.

10 Zeidifard E, Godfrey S, Davies EE. Estimation of cardiac output by a nitrous oxide rebreathing method in adults $\omega$ and children. J Appl Physiol 1976;41:433-8.

11 Chu J, Clements JA, Cotton EK, Klaus MH, Sweet AY, Tooley WH. Neonatal pulmonary ischaemia; clinical $\frac{\digamma}{\mathbb{D}}$ and physiological studies. Pediatrics 1967;40:709-79.

12 Cotton E. Measurement of effective pulmonary blood $\square$ flow in the newborn infant, using a mass spectrometer. Crit Care Med 1976;4:245-7.

13 Tanner JM, Whitehouse RH, Takaishi M. Standards $\frac{O}{\mathbb{P}}$ from birth to maturity for height, weight, height 2 velocity and weight velocity, British children. Arch Dis Child 1966;41:544-7. 
14 Dubois D, Dubois EF. The relation of body surface area to body size. Arch Intern Med 1915;17:868-71.

15 Cotes JE. Lung function: assessment and application in medicine. Oxford: Blackwell, 1979.

16 Ogilvie CM, Forster RE, Blakemore WS, Morton JW. A standardised breath holding technique for the clinical measurement of the diffusing capacity of the lung for carbon monoxide. J Clin Invest 1957;36:1-17.

17 Lewis BM, Lin TH, Noe FE, Hayford Wesling JH. The measurement of pulmonary diffusing capacity for carbon monoxide by a rebreathing method. $J$ Clin Invest 1959;38:2073-86.

18 Polgar G, Promodhat V. Pulmonary function testing in children: techniques and standards. Philadelphia: Saunders, 1971.

19 Barratt-Boyes BG, Wood EH. Cardiac output and related measurements and pressure values in the right heart and associated vessels, together with an analysis of the haemodynamic response to the inhalation of high oxygen mixtures in healthy subjects. $J$ Lab Clin Med 1958;51:72-90.

20 Brandfonbrenner M, Landowne M, Shock NW. Changes in cardiac output with age. Circulation 1955;12:557-66.

21 Guyton AC, Jones CE, Coleman TG. Cardiac output and its regulation. Philadelphia: Saunders, 1973.

22 West J. Ventilation, blood flow and gas exchange. Oxford: Blackwells, 1977.

23 Hamilton WF. Measurement of cardiac output. In: Handbook of physiology. Washington DC: American Physiological Society, 1962:551-84.

24 Kallay MC, Hyde RW, Smith RJ, Rothbard RL, Schreiner BF. Cardiac output by rebreathing in patients with cardiopulmonary diseases. J Appl Physiol 1987;63:201-10. 